\title{
Desempenho de feijão-vagem arbustivo, sob cultivo orgânico em duas épocas $^{1}$
}

\author{
Valdivina Lúcia Vidal²; Ana Maria Resende Junqueira ${ }^{3}$ Nei Peixoto ${ }^{4}$; Ednan Araujo Moraes ${ }^{2}$ \\ ${ }^{2}$ AGENCIARURAL-EE Anápolis, C. Postal 608, 75001-970 Anápolis-GO; ${ }^{3}$ UnB, C. Postal 4.508, 70910-970 Brasília-DF; \\ ${ }^{4}$ AGENCIARURAL/UEG-EE Anápolis; Universidade Estadual de Goiás, Rodovia GO 330, km 241 Anel Viário, $75780-000$ Ipameri- \\ GO; E-mail: luciavidalc@yahoo.com.br
}

\section{RESUMO}

Seis genótipos de feijão-vagem arbustivo foram avaliados em Anápolis-GO, sob sistema orgânico de produção, nos períodos de outono-inverno (2002) e primavera-verão (2002/2003). Avaliou-se a precocidade, produtividade de vagens, peso e número de vagens por planta, total e comercial, peso e número de vagens com defeito (\%), produtividade e peso de 100 sementes. O delineamento experimental utilizado foi de blocos ao acaso, com seis tratamentos (linhagens Hab 1, Hab 19, Hab 39, Hab 46, e as cultivares Coralina e Turmalina), em quatro repetições. Todos os genótipos apresentaram maior rendimento no período de outono-inverno. As cultivares Coralina e Turmalina foram as mais precoces nos dois períodos. As maiores produtividades, total e comercial, observadas no outonoinverno foram apresentadas por 'Coralina' e linhagem Hab 39, superando 'Turmalina', mas igualaram-se às demais linhagens, enquanto que na primavera-verão 'Coralina' mostrou-se superior apenas à linhagem Hab 46

Palavras-chave: Phaseolus vulgaris L., rendimento, produção orgânica.

\begin{abstract}
Evaluation of bush snap beans under organic cropping system, during two periods

Six genotypes of bush snap beans were evaluated in Anápolis, Goiás State, Brazil, during autumn-winter $\left(25^{\text {th }}\right.$ May $-13^{\text {th }}$ August, $2002)$ and spring-summer (12 $2^{\text {th }}$ November, $2002-10^{\text {th }}$ January, 2003) seasons cultivation in an organic cropping system. The experimental design was of randomized blocks, with six treatments (breeding lines Hab 1, Hab 19, Hab 39, Hab 46 and cultivars Coralina and Turmalina), with four replications. All the genotypes resulted in higher yield during autumn-winter season. Cultivars Coralina and Turmalina were earlier in both seasons. 'Coralina' and Hab 39 showed the highest yields, higher than cv. Turmalina, but similar to the other breeding lines. During spring-summer season, 'Coralina' presented better results than Hab 46.
\end{abstract}

Keywords: Phaseolus vulgaris L., yield, organic crop system.

(Recebido para publicação em 25 de agosto de 2005: aceito em 5 de março de 2007)

$\mathrm{F}$ eijão-vagem (Phaseolus vulgaris L.) é uma hortaliça de grande importância econômica e social no Brasil. Destaca-se entre as dez mais consumidas in natura no estado de Goiás. Em 2002, o volume de vagens comercializadas nas CEASAs de Goiás alcançou 5.291 t. O produto é comercializado o ano todo, sendo $94,5 \%$ produzido no estado por pequenas propriedades rurais, empregando-se mão-de-obra familiar e cultivares de crescimento determinado ou indeterminado (Peixoto et al., 2001; CEASA-GO, 2002).

As plantas de crescimento determinado possuem caule ereto, curto, ramificado, inflorescências terminais, além de laterais. Os frutos são vagens de polpa espessa e formato afilado, dentro das quais se desenvolvem as sementes. Diferem do feijão comum pelo baixo teor de fibras nas vagens que são consumidas verdes (Peixoto, 2001; Filgueira, 2003).
As vantagens das cultivares arbustivas são o menor ciclo e a dispensa do tutoramento. As colheitas são concentradas, podendo chegar no máximo a cinco. Outra vantagem é a possibilidade de efetuar uma única colheita, arrancando as plantas no campo para posterior separação das vagens (Peixoto et al., 1997; Pinto et al., 2001a). As mais adaptadas às condições do estado de Goiás são 'Coralina', 'Turmalina' e 'Mimoso Rasteiro AG-461' (Peixoto et al., 1997).

Em Anápolis (GO), a melhor época de semeadura vai de abril a junho (Peixoto et al., 1997), com produtividade variando de 10,4 a 15,5 $\mathrm{t} \mathrm{ha}^{-1}$, peso médio de vagens comerciais de 5,1 a 9,0 gramas, número de vagens por planta de 13,8 a 18,4 e antese das primeiras flores de 46,0 a 48,3 dias.

Em Minas Gerais, os maiores rendimentos médios de vagens comerciais, em sistema tradicional no outono-inverno, das cvs. Novirex e Turmalina são de 8,9 e 9,0 t ha ${ }^{-1}$, respectivamente (Pinto et al., 2001a, 2001b). Oliveira et al. (2001), avaliando linhagens e cultivares de feijão-vagem arbustivas em sistema tradicional, nas condições de Areia-PB, obtiveram produtividades médias variando de 9,4 a 17,6 t ha-1.

A produtividade média nacional de feijão vagem é de $13 \mathrm{t} \mathrm{ha}^{-1}$ para as arbustivas (Blanco et al., 1997). Já a produção média nacional de semente de feijão-vagem, em sistema tradicional, situa-se entre 1,8 e 2,0 t ha ${ }^{-1}$ (Viggiano, 1990). Em Goiás, o feijão-vagem arbustivo apresenta produtividade de semente de 1,5 a 2,8 $\mathrm{tha}^{-1}$, enquanto que o peso médio de 100 sementes varia de 25 a 41 gramas (Peixoto et al., 1993).

Em Anápolis, a produtividade comercial de vagens, usando cultivares

\footnotetext{
${ }^{1}$ Trabalho executado pela primeira autora como parte de dissertação de mestrado em produção vegetal na UnB, Brasília-DF.
} 
arbustivas sob sistema tradicional é de $5 \mathrm{tha}^{-1}$ (AGENCIARURAL, 2003). Possivelmente, a causa seja um intenso ataque de viroses, sobretudo mosaico dourado, embora as áreas tenham recebido pulverizações químicas.

O cultivo do feijão-vagem em Goiás caracteriza-se pelo cultivo tradicional, dentro dos princípios da "Revolução Verde", que preconiza o uso intensivo de insumos químicos, tanto fertilizantes quanto agrotóxicos, para alcançar elevadas produtividades. As limitações desse sistema são a dependência de insumos externos à propriedade, não raro dominados por oligopólios, e a degradação ambiental, além de afetar negativamente a saúde dos agricultores e consumidores destes produtos.

A crescente constatação dos danos ambientais advindos do desenvolvimento descontrolado das práticas insalubres em setores da agricultura tradicional tem reforçado a conscientização cada vez maior de que algo deve ser feito para minimizá-los. Portanto, estão sendo estudados novos modelos agroecológicos de produção, com base em práticas de manejo orgânico, reciclagem de matéria orgânica e menor agressividade ao meio ambiente (Altieri \& Nicholls, 1999).

A demanda por alimentos saudáveis, livres de resíduos tóxicos, bem como a necessidade de preservação ambiental, tem crescido em todo o mundo. A produção orgânica de alimentos pode se tornar uma alternativa viável para aumentar a rentabilidade do setor agropecuário (Saminêz, 1999). O sistema orgânico de produção de hortaliças tem proporcionado efetivo desenvolvimento agronômico em diferentes espécies, alcançando níveis competitivos de produtividade e produtos de elevado padrão comercial (Souza et al., 2001; Souza \& Resende, 2003). Vidal et al. (2003) obtiveram produtividades médias de 1,9 a $3,1 \mathrm{t} \mathrm{ha}^{-1}$ em feijões especiais, em sistema orgânico, superiores aos alcançados no sistema tradicional, em Anápolis-GO.

O Brasil é carente de cultivares de feijão-vagem desenvolvidas para o sistema de cultivo orgânico. A cultivar ideal deve apresentar rusticidade, resistência às pragas e produtividade satisfatória sem a utilização de fertilizantes solúveis.
Segundo Maluf (2002), a produção de sementes orgânicas não tem sido alvo de interesse de grandes empresas, por envolver mudanças nos atuais sistemas de produção. Primavesi (2001) enfatiza que cultivares oriundas de países de clima temperado não apresentam adaptabilidade a climas quentes.

Em Goiás, a produção orgânica ainda é insipiente devido à ausência de tecnologia específica, incluindo cultivares adaptadas ao sistema.

O objetivo deste trabalho foi avaliar genótipos de feijão-vagem arbustivo nas épocas de outono-inverno e primaveraverão, em sistema de cultivo orgânico, em Anápolis-GO, visando a disponibilidade de material genético mais adaptado às condições climáticas da região e às especificidades desse sistema de cultivo.

\section{MATERIAL E MÉTODOS}

Foram conduzidos, a campo, dois experimentos com feijão-vagem arbustivo em sistema orgânico de produção, no outono/inverno (25/05 a 13/ 08/2002) e na primavera-verão (12/11/ 2002 a 10/01/2003), no Setor de Olericultura e Fruticultura da Estação Experimental de Anápolis-GO (EEA) da AGENCIARURAL, em Latossolo vermelho, latitude $16^{\circ} 19^{\prime} 48^{\prime \prime} \mathrm{S}$, longitude 48 58'23" W.Grw e altitude de $1.032 \mathrm{~m}$. O clima é classificado como AW (Köppen), com duas estações bem definidas (seca e chuvosa), com a ocorrência de períodos de estiagem durante a estação chuvosa (veranicos).

O solo foi fertilizado com base nos resultados da análise química e de acordo com os critérios para a produção orgânica (MAPA, 1999; Brasil, 2003). Para viabilizar a conversão ao sistema orgânico, uma área de 1,6 ha foi deixada em pousio com Brachiaria decumbens durante os anos de 1998 a 2000. No verão de 2001/2002 foram semeadas as leguminosas mucuna preta (Stilozobium aterrimum) e crotalária (Crotalaria spectabilis). No período de floração esses materiais foram incorporados superficialmente ao solo. Faixas de terreno com as leguminosas foram deixadas intactas, em torno dos experimentos com o objetivo de aumentar a diversidade de plantas na área, além de servir como barreiras naturais e abrigo para predadores. Parte da área convertida ao sistema orgânico foi dividida em duas glebas: I e II, onde foram conduzidos os experimentos I e II, respectivamente.

Foram avaliados seis genótipos de feijão-vagem de crescimento determinado, sendo quatro linhagens (Hab 1, Hab 19, Hab 39 e Hab 46) e duas cultivares (Coralina e Turmalina), provenientes da EEA, selecionados de materiais genéticos oriundos do Centro Internacional de Agricultura Tropical (CIAT) (Tabela 1). A escolha desses materiais foi baseada em dados disponíveis na EEA e na literatura (Peixoto et al., 1997; Pinto et al, 2001a, b), relativos a resistência às pragas e doenças, à qualidade de vagens e à produtividade em sistema tradicional de cultivo.

O experimento I foi conduzido no período de outono-inverno, logo após a incorporação das leguminosas, com semeadura realizada em 25/05/02, enquanto que o II foi conduzido na primaveraverão (2002/2003), semeado em 12/11/ 02. Nessa área, antecedeu o cultivo de feijões especiais no período de outonoinverno em 2002, também em sistema orgânico.

Para ambos, o delineamento experimental utilizado foi de blocos ao acaso, com seis tratamentos e quatro repetições. Cada parcela foi composta de oito fileiras de plantas com oito metros de comprimento, espaçadas de $50 \mathrm{~cm}$ entre linhas e de $20 \mathrm{~cm}$ entre plantas, num total de cinco plantas por metro de fileira. Para a produção de vagens verdes foram usados cinco metros das quatro fileiras centrais $\left(10 \mathrm{~m}^{2}\right)$ e para a produção de sementes, cinco metros das quatro fileiras laterais $\left(10 \mathrm{~m}^{2}\right)$.

A cultura foi conduzida em sistema orgânico de produção, de acordo com a Lei $n^{\circ} 10.831$ que regulamenta a Agricultura Orgânica (MAPA, 1999; Brasil, 2003).

A análise química do solo na área I, resultou: $\mathrm{pH}$ em água=5,5, $\mathrm{P}$ disponível (extrator Mehlich 1) $=4,0 \mathrm{mg} \mathrm{dm}^{-3}, \mathrm{~K}$ disponível=104,0 $\mathrm{mg} \mathrm{dm}^{-3}, \mathrm{Ca}+\mathrm{Mg}=2,8 \mathrm{cmol}$ $\mathrm{dm}^{-3}, \mathrm{Al}=0,0 \mathrm{cmol} \mathrm{dm}^{-3}$, e matéria orgâni$\mathrm{ca}=26,6 \mathrm{~g} \mathrm{dm}^{-3}$. Já na área experimental II, à época da semeadura, o solo apresentou: pH em água=5,7, P disponível (extrator 
Tabela 1. Características de genótipos de feijão-vagem arbustivo, sob cultivo orgânico, em Anápolis-GO, 2002/2003 (Characteristics of arbustive grean beens, under organic cultivation). Anápolis, AGENCIARURAL-EEA, 2004.

\begin{tabular}{|c|c|c|c|c|c|}
\hline \multirow{2}{*}{ Genótipos } & \multirow{2}{*}{ Cor da flor } & \multirow{2}{*}{$\begin{array}{l}\text { Tipo de } \\
\text { vagem }\end{array}$} & \multirow[t]{2}{*}{ Cor das sementes } & \multicolumn{2}{|c|}{$\begin{array}{l}\text { Vagens no padrão } \\
\text { comercial }\end{array}$} \\
\hline & & & & $\begin{array}{c}\text { Largura } \\
(\mathrm{mm})\end{array}$ & $\begin{array}{c}\text { Comprimento } \\
(\mathrm{cm})\end{array}$ \\
\hline Turmalina & Branca & Achatadas & Brancas & 11,7 & 15,3 \\
\hline Coralina & Roxa & Cilíndricas & $\begin{array}{l}\text { Rajadas de preto e } \\
\text { branco }\end{array}$ & 8,2 & 13,4 \\
\hline Hab 1 & Branca & Achatadas & Brancas & 10,4 & 14,9 \\
\hline Hab 46 & Roxa & Cilíndricas & $\begin{array}{l}\text { Rajadas de preto e } \\
\text { branco }\end{array}$ & 8,6 & 14,1 \\
\hline Hab 19 & Roxa & Cilíndricas & Pretas & 9,4 & 15,0 \\
\hline Hab 39 & Rosa & Cilíndricas & Marrons & 9,6 & 15,0 \\
\hline
\end{tabular}

Fonte: Adaptado de Peixoto (1997).

Tabela 2. Número de dias da semeadura à antese de $50 \%$ das plantas e produtividade de vagens, total e comercial, de genótipos de feijão-vagem arbustivo, no outono-inverno e primavera-verão, sob cultivo orgânico, em Anápolis-GO (Number of days from sowing to anthese of 50\% of plants and total and marketable yield of snap-beans genotypes, in autumnwinter and spring-summer, under organic cultivation in Anapolis, Goias State), 2002/2003. Anápolis, AGENCIARURAL-EEA, 2004.

\begin{tabular}{|c|c|c|c|c|c|c|c|}
\hline \multirow{3}{*}{ Genótipos } & \multicolumn{3}{|c|}{$\begin{array}{c}\text { Dias da semeadura à } \\
\text { antese }\end{array}$} & \multicolumn{4}{|c|}{ Produtividade ( $t$ ha- 1 ) } \\
\hline & \multirow{2}{*}{$\begin{array}{l}\text { Outono- } \\
\text { inverno }\end{array}$} & \multirow{2}{*}{\multicolumn{2}{|c|}{$\begin{array}{l}\text { Primavera- } \\
\text { verão }\end{array}$}} & \multicolumn{2}{|c|}{ Outono-inverno } & \multicolumn{2}{|c|}{ Primavera-verão } \\
\hline & & & & Total & Comercial & Total & Comercia \\
\hline Coralina & 46,3 & 33,3 & c & 12,4 a & 11,1 a & $5,0 \mathrm{a}$ & $2,6 \mathrm{a}$ \\
\hline Turmalina & 46,3 & 33,3 & c & $7,2 \quad b$ & $6,4 \quad b$ & $3,8 \mathrm{a} \mathrm{b}$ & $2,2 \mathrm{a} \mathrm{b}$ \\
\hline Hab 1 & $47,3 \mathrm{a} b$ & 35,5 a & & $10,0 \mathrm{a} \mathrm{b}$ & $8,9 a b$ & $3,1 \mathrm{ab}$ & $1,6 a b$ \\
\hline Hab 19 & 47,5 a & $34,5 a b$ & & $11,2 a b$ & 8,8 a b & $5,2 \mathrm{a}$ & $2,7 \mathrm{a}$ \\
\hline $\mathrm{Hab} 46$ & $47,0 \mathrm{ab}$ & 34,0 a b & & $10,0 \mathrm{a} \mathrm{b}$ & 9,4 a b & $2,4 \quad b$ & $1,2 \quad b$ \\
\hline Hab 39 & $47,5 \mathrm{a}$ & $34,5 a b$ & & $12,1 \mathrm{a}$ & $10,5 \mathrm{a}$ & $3,2 \mathrm{a} \mathrm{b}$ & $1,6 \mathrm{a} \mathrm{b}$ \\
\hline$\overline{\mathrm{CV} \%}$ & 1,0 & 1,4 & & 17,5 & 18,7 & 25,8 & 28,1 \\
\hline
\end{tabular}

Médias seguidas da mesma letra, na coluna, não diferem estatisticamente entre si, pelo teste de Tukey, a 5\% de probabilidade (Means followed by the same letter in the column did not differ from each other by the Tukey test, $\mathrm{P}<0.05)$.

Mehlich 1) $=3,0 \mathrm{mg} \mathrm{dm}^{-3}, \mathrm{~K}=210 \mathrm{mg} \mathrm{dm}^{-3}$, $\mathrm{Ca}+\mathrm{Mg}=2,3 \mathrm{cmol} \mathrm{dm}^{-3}, \mathrm{Al}=0,1 \mathrm{cmol} \mathrm{dm}^{-3}$ e matéria orgânica $=24,1 \mathrm{~g} \mathrm{dm}^{-3}$.

Em ambos os experimentos, as adubações foram feitas com $500 \mathrm{~g} \mathrm{~m}^{-1} \mathrm{de}$ composto orgânico $+30 \mathrm{~g} \mathrm{~m}^{-1} \mathrm{de}$ termofosfato Yoorin, no plantio, e 200 $\mathrm{g} \mathrm{m}^{-1}$ de esterco de aviário puro, bem curtido, aos 20 dias após a semeadura.

O composto orgânico utilizado foi produzido na EEA a partir de palhada de milho verde e esterco de aviário puro, seguindo metodologia de Kiehl (1985) e Souza \& Resende (2003). Pronto para uso resultou na seguinte composição: $\mathrm{pH}$ em água $=6,2, \mathrm{~K}=6,2 \mathrm{~g} \mathrm{~kg}^{-1}, \mathrm{~N}=13,0$ $\mathrm{g} \mathrm{kg}^{-1}, \mathrm{P}=10,3 \mathrm{~g} \mathrm{~kg}^{-1}$ e matéria orgâni$\mathrm{ca}=280 \mathrm{~g} \mathrm{~kg}^{-1}$. plantas da parcela apresentavam, pelo menos, uma flor aberta). Nas colheitas de vagens verdes, obteve-se o número e peso $(\mathrm{g})$ de vagens por parcela $\left(10 \mathrm{~m}^{2}\right)$, número de plantas por parcela, no período inicial da colheita, que geraram os dados de produtividade $\left(\mathrm{t} \mathrm{ha}^{-1}\right)$, número de vagens por planta, peso da vagem, total e comercial (vagens desprovidas de injúrias e danos causados por pragas e patógenos), além do peso e número de vagens com defeito.

Para a colheita de sementes, as plantas foram arrancadas e trilhadas, obtendo-se o peso por parcela e a produtividade $\left(\mathrm{t} \mathrm{ha}^{-1}\right)$. Foram retiradas amostras, ao acaso, de 100 sementes por parcela, registrando-se o peso das mesmas.

Os dados foram submetidos à análise de variância e as médias comparadas pelo teste de Tukey, ao nível de 5\% de probabilidade.

\section{RESULTADOS E DISCUSSÃO}

Foram observadas diferenças significativas entre genótipos para a antese das primeiras flores, produtividade e peso médio de vagens (total e comercial), nos dois períodos. Para o número de vagens por planta, houve diferença significativa somente na primavera-verão, enquanto que para a porcentagem de peso e número de vagens com defeito, além da produtividade média de sementes houve diferença significativa no outono-inverno.

\section{Precocidade}

A antese das primeiras flores, no período de outono-inverno, teve início no $46^{\circ}$ dia após a semeadura e, na primavera-verão, ocorreu no $33^{\circ}$ dia. As cultivares Coralina e Turmalina foram mais precoces que Hab 19 e Hab 39 no outono-inverno, superando a todas as linhagens, no período de primavera-verão (Tabela 2).

\section{Produtividade de vagens}

As colheitas de vagens verdes, num total de três, tiveram início 64 dias após a semeadura, no outono-inverno. A cultivar Coralina superou a cultivar Turmalina e igualou-se às demais linhagens em produtividade média, total e comercial.

Na primavera-verão as colheitas de vagens verdes, em número de duas, ti- 
Tabela 3. Número de vagens por planta e peso de vagens, total e comercial, de genótipos de feijão-vagem arbustivo, no outono-inverno e primavera-verão, sob cultivo orgânico, em Anápolis-GO, 2002/2003 (Number of poods per plant total and marketable weight of bush snap beans genotypes, in autumn-winter and spring-summer, under organic cultivation). Anápolis, AGENCIARURAL-EEA, 2004.

\begin{tabular}{|c|c|c|c|c|c|c|c|c|c|c|}
\hline \multirow{3}{*}{ Genótipos } & \multicolumn{6}{|c|}{ Vagens por planta $\left(n^{\circ}\right)$} & \multicolumn{4}{|c|}{ Peso da vagem (g) } \\
\hline & \multicolumn{2}{|c|}{ Outono-inverno } & \multicolumn{4}{|c|}{ Primavera-verão } & \multicolumn{2}{|c|}{ Outono-inverno } & \multicolumn{2}{|c|}{ Primavera-verão } \\
\hline & Total & Comercial & Total & & Comercia & & Total & Comercial & Total & Comercial \\
\hline Coralina & $17,0 \mathrm{a}$ & $14,1 \mathrm{a}$ & $9,4 a$ & $\mathrm{~b}$ & 4,5 & $\mathrm{~b}$ & $7,2 \mathrm{a} \mathrm{b}$ & $7,7 a b$ & $7,6 \mathrm{a}$ & $8,3 a$ \\
\hline Turmalina & $11,3 \mathrm{a}$ & $9,5 \mathrm{a}$ & 7,5 & b c & 4,0 & $b$ & 7,8 a & $8,3 \mathrm{a}$ & $7,7 \mathrm{a}$ & $8,3 \mathrm{a}$ \\
\hline Hab 1 & $15,2 \mathrm{a}$ & $13,0 \mathrm{a}$ & 7,3 & b c & 3,6 & $b$ & $8,3 \mathrm{a}$ & $8,6 \mathrm{a}$ & $7,6 \mathrm{a}$ & $7,7 \mathrm{a} \mathrm{b}$ \\
\hline Hab 19 & $17,6 a$ & $12,3 \mathrm{a}$ & $12,3 a$ & & $6,5 \mathrm{a}$ & & $5,9 \quad b$ & $6,7 \quad b$ & 6,6 a & 6,5 \\
\hline Hab 46 & $15,9 a$ & $12,3 \mathrm{a}$ & 5,6 & c & 2,8 & b & $7,1 \mathrm{a} \mathrm{b}$ & 7,8 a b & $7,0 \mathrm{a}$ & $6,8 \quad b$ \\
\hline Hab 39 & $14,1 \mathrm{a}$ & $11,0 \mathrm{a}$ & 6,6 & b c & 3,4 & $\mathrm{~b}$ & $7,6 \mathrm{a}$ & $8,4 \mathrm{a}$ & $7,8 \mathrm{a}$ & $7,5 \mathrm{ab}$ \\
\hline CV\% & 20,0 & 21,2 & 20,0 & & 20,4 & & 7,5 & 7,9 & 9,1 & 6,7 \\
\hline
\end{tabular}

Médias seguidas da mesma letra, na coluna, não diferem estatisticamente entre si, pelo teste de Tukey, a 5\% de probabilidade (Means followed by the same letter in the column did not differ from each other by the Tukey test, $\mathrm{P}<0.05$ ).

veram início 52 dias após a semeadura. A linhagem Hab 19 e a cultivar Coralina foram mais produtivas do que a linhagem Hab 46 e igualaram-se aos demais genótipos quanto às produtividades médias, total e comercial (Tabela 2).

Os genótipos arbustivos avaliados em sistema orgânico foram mais produtivos no outono-inverno, devido à menor pressão de pragas e baixo estresse decorrente do calor. Esses resultados concordam com aqueles obtidos por Peixoto et al. (1997) que, comparando as épocas de semeadura, observaram ser abril a junho o período mais favorável para o cultivo tradicional de feijão-vagem arbustivo em Goiás.

\section{Número de vagens por planta}

$\mathrm{O}$ número de vagens por planta foi de 15,2 para vagens totais e de 12,1 para vagens comerciais, não havendo diferença estatística significativa entre os genótipos, no outono-inverno (Tabela 3 ). Esses valores situaram-se dentro das médias encontradas no sistema tradicional por Pinto et al. (2001b) e Peixoto et al. (1997).

Na primavera-verão, a linhagem Hab 19 apresentou o maior número de vagens totais por planta, seguida da cultivar Coralina, enquanto que para o número de vagens comerciais, Hab 19 foi estatisticamente superior a todos os genótipos (Tabela 3).

\section{Peso da vagem}

Os maiores pesos de vagens total e comercial ocorreram nas linhagens Hab 1, Hab 39 e na cultivar Turmalina, que apresentaram diferença estatística sig-
Tabela 4. Produtividade e peso de 100 sementes, no outono-inverno, porcentagem de peso e número de vagens com defeito, em genótipos de feijão-vagem arbustivo, sob cultivo orgânico, em Anápolis-GO, 2002/2003 (Yield and weight of 100 seeds, in autums-winter, percentage of weight and number of snap-beans with defective pods of bush snap-beans, under organic cultivation). Anápolis, AGENCIARURAL-EEA, 2004.

\begin{tabular}{|c|c|c|c|c|c|c|}
\hline \multirow{3}{*}{ Genótipos } & \multicolumn{2}{|c|}{$\begin{array}{c}\text { Semente no } \\
\text { Outono-inverno }\end{array}$} & \multicolumn{4}{|c|}{ Vagens com defeitos } \\
\hline & \multirow{2}{*}{$\begin{array}{l}\text { Produtividade } \\
\text { (t ha-1) }\end{array}$} & \multirow{2}{*}{$\begin{array}{l}\text { Peso de } 100 \\
\text { sementes } \\
\text { (g) }\end{array}$} & \multicolumn{2}{|c|}{ Outono-inverno } & \multicolumn{2}{|c|}{ Primavera-verão } \\
\hline & & & $\%$ peso & \%número & $\%$ peso & $\%$ número \\
\hline Coralina & $1,9 a b$ & $33,5 \mathrm{a}$ & 10,6 & 17,0 & $47,7 \mathrm{a}$ & $52,5 \mathrm{a}$ \\
\hline Turmalina & $1,3 \quad b$ & $31,0 \mathrm{a}$ & 11,3 & 16,0 & $44,2 \mathrm{a}$ & $48,3 a$ \\
\hline Hab 1 & $1,5 \quad b$ & 33,3 a & 11,0 & 14,8 & $49,2 \mathrm{a}$ & $49,5 \mathrm{a}$ \\
\hline Hab 19 & $1,8 \mathrm{ab}$ & 30,3 a & $21,5 \mathrm{a}$ & 30,3 a & $48,0 \mathrm{a}$ & $47,3 \mathrm{a}$ \\
\hline Hab 46 & $1,7 \mathrm{ab}$ & $35,3 a$ & $15,3 a b$ & 23,0 a b & $53,5 a$ & $52,0 \mathrm{a}$ \\
\hline Hab 39 & $2,3 \mathrm{a}$ & $33,0 \mathrm{a}$ & $14,0 \quad b$ & $21,5 \quad b$ & $50,3 \mathrm{a}$ & $49,5 \mathrm{a}$ \\
\hline CV\% & 17,1 & 7,8 & 19,7 & 18,1 & 11,3 & 10,3 \\
\hline
\end{tabular}

Médias seguidas da mesma letra, na coluna, não diferem estatisticamente entre si, pelo teste de Tukey, a 5\% de probabilidade (Means followed by the same letter in the column did not differ from each other by the Tukey test, $\mathrm{P}<0.05$ ).

nificativa em relação à linhagem $\mathrm{Hab}$ 19, que foi a de menor peso. A cultivar Coralina e a linhagem Hab 46 igualaram-se às maiores médias no período de outono-inverno (Tabela 3).

Na primavera-verão, Coralina e Turmalina superaram as linhagens Hab 19 e Hab 46 para peso de vagens comerciais. Para peso de vagens total não foi observada diferença estatística significativa entre os genótipos (Tabela 3).

Peso e número de vagens com defeito $(\%)$

A linhagem Hab 19 seguida de Hab 46 apresentaram as maiores perdas em peso e número de vagens com defeito, no outono-inverno (Tabela 4). A alta porcentagem de perda apresentada por
Hab 19, provavelmente, foi devido à sua maior suscetibilidade ao mosaico dourado, conforme sintomas visuais observados à campo.

Foi de $48,8 \%$ o peso de vagens com defeito e de $49,8 \%$ o número de vagens com defeito, não havendo diferença estatística significativa entre os genótipos no período de primavera-verão (Tabela 4). Essa elevada quantidade de vagens com defeito se deu em função da maior incidência de doenças, sendo um fator responsável pela menor produtividade observada no período.

Produtividade e peso de 100 sementes

A colheita de sementes ocorreu aos 119 dias após a semeadura, no outono- 
inverno. Foram observadas diferenças estatísticas significativas entre os genótipos para a produtividade de semente. Hab 39 foi a mais produtiva (2,3 t ha' ${ }^{-1}$, seguida de 'Coralina', as quais atingiram rendimentos semelhantes à média nacional, que se situa entre 1,8 a 2,0 t ha $^{-1}$ (Viggiano, 1990), enquanto que 'Turmalina' e Hab 1 foram as menos produtivas (Tabela 4).

O peso de 100 sementes variou de 30,3 a 35,3 gramas, não tendo sido observada diferença significativa entre os genótipos. Esses pesos foram inferiores e o ciclo excedeu em 6 dias aos observados por Peixoto et al. (1993), em sistema tradicional de produção de sementes de feijão-vagem arbustivo, na mesma região.

Na primavera-verão não houve produção de sementes devido às precipitações pluviais, intensas e contínuas, e a incidência de doenças.

A linhagem Hab 39 e a cultivar Coralina apresentam potencial para a produção de sementes orgânicas, sendo outono-inverno a época adequada para produção de sementes.

Apesar de existir uma tendência de que nos primeiros anos de cultivo orgânico ocorram menores rendimentos do que nos similares tradicionais devido à não estabilização do sistema orgânico (Darolt, 2002), verificou-se que o cultivo de feijão-vagem arbustivo em sistema orgânico de outono-inverno, em Anápolis, primeiro ano, comportou-se semelhantemente ao observado sob sistema tradicional, em conformidade com os rendimentos obtidos por Pinto et al. (2001 a, b) em Minas Gerais, e Peixoto et al. (1997), em Goiás.

As médias da produtividade, do peso de vagens comerciais e do número de vagens por planta igualaram-se àquelas obtidas por Peixoto et al. (1997) para linhagem Hab 39, no sistema tradicional de outono-inverno e, superaram às de primavera-verão para todos os genótipos. Portanto, o cultivo orgânico de feijão-vagem arbustivo em AnápolisGO é viável, no período de outono-inverno, quando foram observados os melhores resultados de desempenho agronômico.

A cultivar Coralina, a princípio, pode ser recomendada para plantio em sistema de cultivo orgânico, na região de Anápolis-GO. A linhagem Hab 39 poderá ser disponibilizada para produtores da região como nova cultivar apropriada para plantio em sistema orgânico, em futuro próximo.

\section{REFERÊNCIAS}

AGÊNCIA GOIANA DE DESENVOLVIMENTO RURAL E FUNDIÁRIOAGENCIARURAL. 2003. Plano Municipal de Ações Integradas. Anápolis: AGENCIARURAL. 30p.

ALTIERI M; NICHOLLS CI. 1999. Ecologically based pest management: a key pathway to achieving agroecosystem health. In: NICHOLLS CI; GARCIA MA; ALTIERI M. Curso de agroecologia: Workshop sobre agroecologia e desenvolvimento sustentável. Campinas: UNICAMP. v. 2, VI.6.

BLANCO MCSG; GROPPO GA; TESSARIOLI NETO J. 1997. Feijão-vagem. Manual Técnico das Culturas, Campinas 8: 63-65.

BRASIL. Lei $\mathrm{N}^{\circ} 10.831$ de 23 de dezembro de 2003. 2003. Dispõe sobre agricultura orgânica. Diário Oficial da União, Brasília-DF.

BURG IC; MAYER PH. 2001. Alternativas ecológicas para prevenção e controle de pragas e doenças. Francisco Beltrão, PR: Grafit. 266p.

CENTRAIS DE ABASTECIMENTO DO ESTADO DE GOIÁS-CEASA-GO. 2002. Análise Conjuntural. Goiânia: CEASA-GO. 118p.

DAROLT MR. 2002. Agricultura Orgânica: inventando o futuro. Londrina: IAPAR. 250p.

FILGUEIRA FAR. 2003. Novo manual de olericultura: agrotecnologia moderna na produção e comercialização de hortaliças. 3. ed. Viçosa: Universidade Federal de Viçosa. 412p.

KIEHL EJ. 1985. Fertilizantes orgânicos. São Paulo: Agronômica Ceres. 492p.

MALUF WR. 2002. Sementes orgânicas de hortaliças. Horticultura Brasileira. 20. Suplemento 2. CD-ROM.

MINISTÉRIO DAAGRICULTURA, PECUÁRIA E ABASTECIMENTO-MAPA. 1999. Normalização para a produção de produtos orgânicos. Brasília: MAPA (IN n. $\left.{ }^{\circ} 07,17 / 05 / 1999\right)$.
OLIVEIRA AP; PEIXOTO N; VALADARES WA; TAVARES SOBRINHO J; ALVES AU; BRUNO GB; ALVES EU. 2001. Avaliação de linhagens e cultivares arbustivas de feijão-vagem nas condições de Areia-PB. Agropecuária Técnica 22: 21-25.

PEIXOTO N; SILVA LO; THUNG MDT; SANTOS G. 1993. Produção de sementes de linhagens e cultivares arbustivas de feijão-vagem em Anápolis-GO. Horticultura Brasileira 11: 151-152.

PEIXOTO N; THUNG MDT; SILVA LO; FARIAS JG; OLIVEIRA EB; BARBEDO ASC.; SANTOS G. 1997. Avaliação de cultivares arbustivas de feijão-vagem, em diferentes ambientes do Estado de Goiás. Boletim de Pesquisa, Goiânia: EMATER-GO, n.1, 20p.

PEIXOTO N. 2001. Interação genótipos $x$ ambiente e divergência genética em feijão-vagem (Phaseolus vulgaris L.). 67p. UNESP, Jaboticabal-SP. (Tese doutorado)

PEIXOTO N; MORAES EA; MONTEIRO JD; THUNG MDT. 2001. Seleção de linhagens de feijão-vagem de crescimento indeterminado para cultivo no Estado de Goiás. Horticultura Brasileira 19: 85-88.

PINTO CMF; VIEIRA C; CALDAS MT. 2001a. Idade de colheita do feijão-vagem anão cultivar Novirex. Horticultura Brasileira 19: 163167.

PINTO CMF; VIEIRA RF; VIEIRA C; CALDAS MT. 2001b. Comportamento de cultivares de feijão-vagem anão em diferentes épocas de plantio na Zona da Mata de Minas Gerais. Horticultura Brasileira 19: 273.

PRIMAVESI AM. 2001. Manejo ecológico de solos tropicais na horticultura. Horticultura Brasileira v.19. Suplemento. CD-ROM.

SAMINÊZ TC. 1999. Produção orgânica de alimentos. Horticultura Brasileira, v.17. Artigo de capa.

SOUZA JL; BALBINO JMS; COSTA H; PREZOTTI LC; VENTURA JA; BOREL RM. 2001. Pesquisas em Hortaliças Orgânicas: a experiência do INCAPER. Horticultura Brasileira, Brasília, v.19. Suplemento 2. CDROM. Palestra.

SOUZA JL; RESENDE P. 2003. Manual de Horticultura Orgânica. Viçosa: Aprenda Fácil. $564 \mathrm{p}$.

VIDAL VL; PEIXOTO N; MORAES EA; MOREIRA JA. 2003. Avaliação de genótipos de feijões especiais em sistema orgânico. Horticultura Brasileira, v.21. Suplemento 1. CD-ROM.

VIGGIANO J. 1990. Produção de sementes de feijão-vagem. In: CASTELLANE PD; NICOLOSI WM; HASEGAWA M. Produção de sementes de hortaliças. Jaboticabal-SP: UNESP, FCAV. p.127-140. 